I would suggest that the time spent on taking the F.R.C.S. would be better employed on a diploma in ophthalmology, in attending and working in allied medical clinics, in studying in a recognised ophthalmic school and hospital for two or three or more years, and in obtaining at the end a certificate of competence given by the chief or by the medical staff which alone would allow the recipient to call himself an ophthalmic surgeon and which would confirm a thorough knowledge of the medical side of the subject and a sound surgical skill as well.

With a team of full time assistants many more really capable ophthalmologists could be turned out, though naturally amongst them there would only rarely be a surgeon who was exceptional by virtue of a natural aptitude as a craftsman and unusual mental equipment as a strategist.

Yours truly,

O. Gayer Morgan.

\title{
OBITUARY
}

\section{G. W. ROLL}

WE regret to record the death of Mr. Grahame Winfield Roll on February 21, at the age of 79 years after a long period of ill health.

Roll was educated at Bedford School, Christ's College, Cambridge, and St. Thomas's Hospital, qualifying in 1886 . In 1887 he took the M.B. and B.Ch.(Cambridge). Early in his career he became interested in ophthalmology and was ophthalmic house surgeon at St. Thomas's Hospital. He afterwards held a resident appointment at the Leicester General Hospital for a considerable time. Returning to London he spent a few years in general practice in Kensington, in the meantime continuing the study of ophthalmology at Moorfields and the Royal Westminster Ophthalmic Hospital. In 1898 he took the F.R.C.S.(Eng.) and afterwards devoted himself entirely to ophthalmology.

He was appointed to the staff of the Royal Westminster Ophthalmic Hospital in 1900 and retired on reaching the age limit in 1922. For many years he was also ophthalmic surgeon to the St. Mary's Hospital for Women and Children, Plaistow. He continued in practice until 1939, when failure of health compelled his retirement. 
Roll was a most pairistaking and conscientious worker. During the many years that the writer was associated with him at the Royal Westminster Ophthalmic Hospital he was hardly ever absent from his clinic except during his short annual holiday, always arriving early and remaining until the last case was finished. He was a sound clinician and his opinion on a difficult case was often most helpful. As an operator his work was characterised by great care and attention to detail. He was deeply interested in the welfare of the Hospital, loved his work there, and was popular with both patients and students. He was a very regular attendant at meetings of the Ophthalmological Society and Ophthalmic Section of the Royal Society of Medicine, although he rarely took part in discussions owing to his diffident and retiring disposition.

He was unmarried, and his chief interests, apart from his work, were ornithology and sailing. For many years he lived with his sister, Miss M. F. Roll, who survives him, and to whom we extend our sympathy in her bereavement.

\section{NOTES}

WE regret to record the sudden death of Dr.

Deaths Victor George Walker which occurred at his home in Ipswich in February last.

Walker received his education in Ireland and was of Trinity College, Dublin. Having taken his B.A. in 1918, he proceeded M.B., B.Ch. in the following year and M.D. in 1921. He took the D.O.M.S. in 1923 and was also F.R.C.S. Edin. At various times he had been House Surgeon at the Royal Westminster Ophthalmic Hospital and chief clinical assistant at Moorfields as well as Ophthalmic Surgeon to the Metropolitan Hospital. Walker joined the Ophthalmological Society of the United Kingdom in 1926. At Ipswich he was Ophthalmic Surgeon to the East Suffolk and Ipswich Hospital and he also held an honorary ophthalmic post in connexion with the Harwich and Dovercourt Hospital. He succeeeded the late H. M. Gilmour at Ipswich in 1929 and quickly earned a good reputation in East Anglia. In this he maintained the high standard of conscientious work in those parts which dates from the days of the late W. W. Sinclair. His death in the prime of life is a great blow to many friends.

As we go to press we regret to record the death of $\mathrm{Mr}$. C. H. Usher, late of Aberdeen; we hope to include a memoir of him in our next number. 